\title{
Results of surgical repair of atrioventricular septal defect with double-orifice left atrioventricular valve
}

\author{
Gerard J. F. Hoohenkerk, MD, ${ }^{\mathrm{a}}$ Arnold C. G. Wenink, MD, PhD, ${ }^{\mathrm{c}}$ Paul H. Schoof, MD, PhD, ${ }^{\mathrm{a}}$ \\ Dave R. Koolbergen, MD, PhD, ${ }^{a}$ Eline F. Bruggemans, MSc, ${ }^{a}$ Mary Rijlaarsdam, $\mathrm{MD},{ }^{\mathrm{b}}$ and \\ Mark G. Hazekamp, MD, $\mathrm{PhD}^{\mathrm{a}}$
}

\begin{abstract}
Objective: The outcome of surgical correction of atrioventricular septal defect with double-orifice left atrioventricular valve has improved in recent years but is still reported to be associated with high mortality and reoperation rates. Controversy exists about the management of the accessory orifice. We evaluated our results with correction of atrioventricular septal defect with double-orifice left atrioventricular valve.
\end{abstract}

\begin{abstract}
Methods: Between 1975 and 2006, 21 patients underwent correction of atrioventricular septal defect with double-orifice left atrioventricular valve. Clinical data were obtained by means of retrospectively reviewing inpatient and outpatient medical records. To evaluate the influence of double-orifice left atrioventricular valve on mortality and the need for reoperation, a comparison was made with 291 consecutive patients who, during the same period, underwent correction of atrioventricular septal defect without double-orifice left atrioventricular valve.
\end{abstract}

Results: None of the 21 patients with double-orifice left atrioventricular valve had undergone a previous operation. The accessory orifice was managed with different techniques depending on the severity of the regurgitation. There was no in-hospital mortality, and there were 3 late deaths. Seven patients required 12 reoperations, 7 for left atrioventricular valve insufficiency. Double-orifice left atrioventricular valve had no influence on mortality but was a significant predictor for reoperation compared with repair of atrioventricular septal defect without double-orifice left atrioventricular valve. At the latest follow-up, all 18 survivors were in New York Heart Association functional class I without medication. Only 1 patient showed residual mild left atrioventricular valve insufficiency.

Conclusion: Atrioventricular septal defect with double-orifice left atrioventricular valve can be repaired with low mortality. However, double-orifice left atrioventricular valve is a predictor for reoperation. The accessory orifice is often competent and should then be left untouched. If regurgitation of the accessory orifice is present, this is best managed with suture or patch closure.

Results of surgical correction of atrioventricular septal defect (AVSD) have improved in recent years. However, valve anomalies and left atrioventricular valve (LAVV) regurgitation remain risk factors for mortality and reoperation. ${ }^{1-3}$ Double-orifice left atrioventricular valve (DO-LAVV) is an uncommon but surgically important valve abnormality. It can occur as an isolated malformation but is most often associated with AVSD. Management of the accessory orifice is controversial. We present our 30-year experience with surgical repair of AVSD with DO-LAVV using different strategies to manage the accessory orifice. We evaluated outcomes by comparing the results of repair of AVSD with DO-LAVV with those of repair of AVSD without DO-LAVV.

\footnotetext{
From the Departments of Cardiothoracic Surgery, ${ }^{\mathrm{a}}$ Pediatric Cardiology, ${ }^{\mathrm{b}}$ and Anatomy, ${ }^{\mathrm{c}}$ Leiden University Medical Center, Leiden, The Netherlands.

Received for publication June 26, 2008; revisions received March 13, 2009; accepted for publication May 15, 2009; available ahead of print June 29, 2009.

Address for reprints: Gerard J. F. Hoohenkerk, MD, Department of Cardio-Thoracic Surgery, Hagaziekenhuis location Leyenburg, The Hague, PO Box 40551, 2504 LN The Hague, The Netherlands (E-mail: g.hoohenkerk@hagaziekenhuis.nl). J Thorac Cardiovasc Surg 2009;138:1167-71 $0022-5223 / \$ 36.00$

Copyright (c) 2009 by The American Association for Thoracic Surgery doi:10.1016/j.jtcvs.2009.05.012
}

\section{MATERIALS AND METHODS \\ Patient Population}

Between January 1975 and May 2006, 312 consecutive patients underwent surgical intervention for AVSD at our institution. Complete AVSD was observed in $209(67.0 \%)$ patients, partial AVSD was observed in 76 $(24.4 \%)$ patients, and intermediate AVSD was observed in $27(8.6 \%)$ patients. An intermediate form of AVSD was defined as having a "scooped out" interventricular septum, with the atrioventricular (AV) valves being connected to the top of the septum by fibrous tissue "curtains" and tendinous chordae, consequently resulting in a small or absent ventricular septal defect component. Twenty-one $(6.7 \%)$ patients had AVSD with DOLAVV, of whom 9 had a complete AVSD, 9 had a partial AVSD, and 3 had an intermediate AVSD. In 17 patients DO-LAVV was diagnosed preoperatively by means of echocardiographic analysis, and in 4 patients it was discovered at the time of the operation. Demographic and clinical characteristics for patients with and without DO-LAVV are summarized in Table 1.

For the 21 patients with DO-LAVV, median age at the time of surgical correction of AVSD was 8.2 months (range, 1.4 months to 11.9 years). Thirteen repairs were performed in infants younger than 1 year, and 9 repairs were performed in infants younger than 6 months. All patients underwent primary repair.

\section{Operative Technique}

All corrections of AVSD with DO-LAVV were performed by using cardiopulmonary bypass with moderate hypothermia and cold crystalloid cardioplegia. In patients with a complete AVSD, a 2-patch method was used with different patch materials (autologous, heterologous pericardium, or 


\section{Abbreviations and Acronyms \\ AV $\quad=$ atrioventricular \\ AVSD $=$ atrioventricular septal defect \\ DO-LAVV $=$ double-orifice left atrioventricular valve \\ LAVV $=$ left atrioventricular valve}

Dacron). In patients with a partial AVSD or intermediate AVSD, closure of the atrial septal defect was performed with autologous or heterologous pericardial patches. Closure of the cleft in the left AV valve was performed completely or partially when total closure would result in obstruction. The accessory orifice was left intact when competent. One-stage repair was performed in the 3 patients with associated coarctation. Intraoperative echocardiographic analysis was used routinely since 1999 in all patients. Before that time, echocardiography was not available in the operation room.

\section{Data Acquisition}

Data on survival and need for reoperation were collected for all patients with AVSD by retrospectively reviewing both inpatient and outpatient medical records. In-hospital mortality was defined as death before hospital discharge or within 30 days after the operation. The closing interval for follow-up was from February 2006 to December 2006. For patients with AVSD and DO-LAVV, preoperative echocardiographic reports, cardiac catheterization reports, or both; operative notes; and the latest echocardiographic reports were also reviewed. Recent echocardiographic Doppler studies were present for all surviving patients with AVSD and DO-LAVV. The study was approved by the ethics committee of our institution.

\section{Statistical Analysis}

The SPSS statistical software program for Windows (version 14.0.2; SPSS, Inc, Chicago, Ill) was used to perform the data analysis. Data are expressed as medians and ranges or frequencies and percentages, where appropriate. Estimates of survival and freedom from reoperation were obtained by using the Kaplan-Meier method. For comparison between repair of AVSD with DO-LAVV and repair of AVSD without DO-LAVV, the log-rank test was used.

\section{RESULTS \\ Preoperative LAVV Function}

For the 21 patients with DO-LAVV, LAVV function was evaluated preoperatively by means of echocardiographic analysis, angiographic analysis, or both depending on the era of operation. In patients with complete $\operatorname{AVSD}(n=9)$, LAVV regurgitation of the true orifice was mild in 4 patients, moderate in 4 patients, and severe in 1 patient. In patients with partial AVSD $(\mathrm{n}=9)$, it was mild in 1 patient, moderate in 6 patients, and severe in 2 patients. In patients with intermediate AVSD $(\mathrm{n}=3)$, regurgitation was mild in 2 patients and severe in 1 patient. None of the patients with AVSD with DO-LAVV had valvular stenosis.

\section{Accessory Orifice Characteristics}

The accessory orifice was either located in the posterior bridging leaflet (sometimes close to the junction of the posterior bridging leaflet and the mural leaflet; $\mathrm{n}=18$ ) or in the anterior bridging leaflet (sometimes close to the junction of
TABLE 1. Patient characteristics

\begin{tabular}{lcc}
\hline & AVSD with & AVSD without \\
& DO-LAVV $(\mathbf{n}=\mathbf{2 1})$ & DO-LAVV $(\mathbf{n}=\mathbf{2 9 1})$ \\
\hline Median age (range) & 8.2 mo $(1.4 \mathrm{mo}-11.9 \mathrm{y})$ & $7.1 \mathrm{mo}(0.5 \mathrm{mo}-30.4 \mathrm{y})$ \\
Male sex & $10(47.6 \%)$ & $142(48.8 \%)$ \\
Down syndrome & $9(42.9 \%)$ & $152(52.2 \%)$ \\
Complete AVSD & $9(42.9 \%)$ & $200(68.7 \%)$ \\
Partial AVSD & $9(42.9 \%)$ & $67(23.0 \%)$ \\
Intermediate AVSD & $3(14.3 \%)$ & $24(8.2 \%)$ \\
Coarctation aortae & $3(14.3 \%)$ & $8(2.7 \%)$ \\
Tetralogy of Fallot & 0 & $24(8.2 \%)$ \\
LVOT obstruction & 0 & $2(0.7 \%)$
\end{tabular}

$\overline{A V S D}$, Atrioventricular septal defect; $D O-L A V V$, double-orifice left atrioventricular valve; $L V O T$, left ventricular outflow tract.

the anterior bridging leaflet and the mural leaflet; $\mathrm{n}=3$ ). The true orifice and the accessory orifice were each supported by their own tension apparatus. Depending on the location of the accessory orifice, the chords of the true orifice and the accessory orifice might converge and insert into a posterior or anterior papillary muscle. The chords of the accessory orifice then usually formed a "parachute." In 3 patients with partial AVSD and an accessory orifice in the posterior bridging leaflet next to the mural leaflet, the mural leaflet was reported to be less developed than normal. In 14 patients regurgitation of the accessory orifice was observed (mild in 1 patient, moderate in 8 patients, and severe in 5 patients; see Figure 1).

\section{Surgical Procedure}

Cleft. In patients with complete AVSD $(n=9)$, the cleft was closed completely in 3 patients, partially in 5 patients, and not closed in 1 patient. In patients with partial AVSD $(n=9)$, the cleft was closed completely in 2 patients, partially in 5 patients, and not closed in 2 patients. In the 3 patients with intermediate AVSD, the cleft was closed partially in all. Cleft closure was always performed with interrupted sutures.

Accessory orifice. In patients with regurgitation of the accessory orifice $(n=14)$, the regurgitation of the accessory orifice was repaired. Severe regurgitation of the accessory orifice was repaired with sutures $(n=1)$, patches $(n=2)$, or resection of the tissue bridge and division of the papillary muscle of the accessory orifice $(n=2)$. Moderate regurgitation of the accessory orifice was repaired mostly with sutures $(\mathrm{n}=7)$ and in 1 patient with a patch. In the single patient with mild regurgitation of the accessory orifice, the accessory orifice was repaired with sutures. In all 7 patients without regurgitation of the accessory orifice, the accessory orifice was left untouched. The AV valve was repaired as a 3-leaflet valve.

\section{Follow-up}

Follow-up data were complete for all 21 patients with DO-LAVV. Three patients without DO-LAVV were lost to follow-up. The median follow-up period was 11.2 years (range, 0.4-24.3 years) for patients with DO-LAVV and 


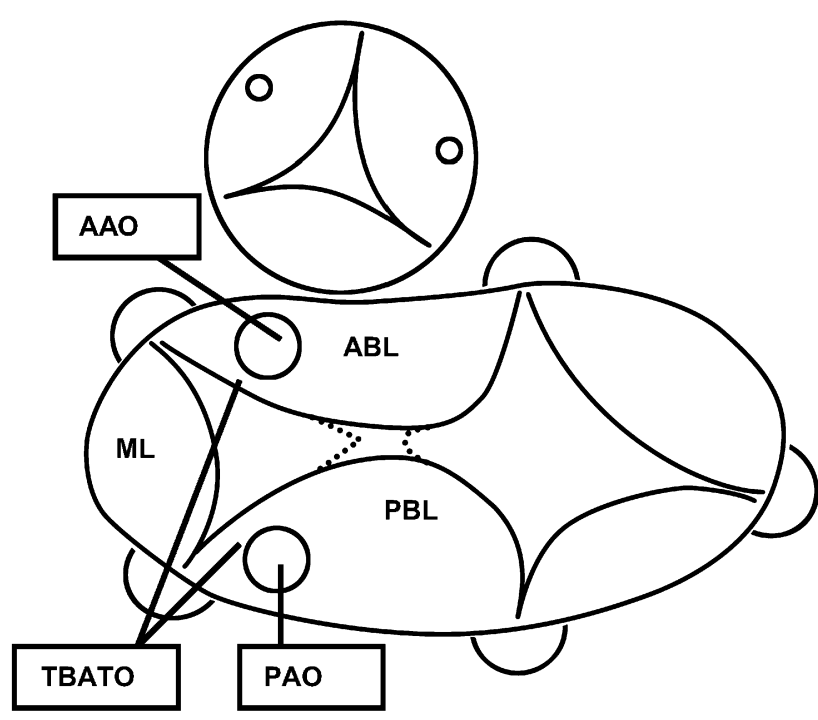

FIGURE 1. Location of the accessory orifice. $A B L$, Anterior bridging leaflet; $P B L$, posterior bridging leaflet; $M L$, mural leaflet; $A A O$, accessory orifice in the anterior bridging leaflet; $P A O$, accessory orifice in the posterior bridging leaflet; TBATO, tissue bridge between the accessory orifice and true orifices.

10.0 years (range, $0-29.3$ years) for patients without DOLAVV.

\section{Mortality}

Among the patients with DO-LAVV, there was no early mortality. There were 3 late deaths. One patient died of latephase sepsis, 1 patient died of respiratory failure, and 1 patient died of cardiac failure. Estimated overall survival rates were $89.9 \%$ at 5 years and $84 \%$ at 10 and 15 years (Figure 2). For patients without DO-LAVV, the estimated survival rates at 5,10 , and 15 years were $90.6 \%, 90.6 \%$, and $88.9 \%$, respectively. The log-rank test showed no statistically significant difference in overall survival for patients with DO-LAVV compared with patients without DO-LAVV $(P=.61)$.

\section{Reoperation}

Seven patients with DO-LAVV required 12 reoperations. Two patients underwent 1 reoperation, and 5 patients underwent 2 reoperations. The median interval to the first reoperation was 1.0 year (range, $0.2-2.2$ years). All first reoperations occurred within 2.5 years after the initial repair. Details for patients undergoing reoperation are noted in Table 2.

Of the patients undergoing reoperation, 1 patient had complete AVSD, 3 patients had partial AVSD, and 3 patients had intermediate AVSD. Incompetence of the true orifice was the most frequent indication for reoperation (7/12 reoperations). Other indications for reoperation were LAVV stenosis $(n=2)$, left ventricular outflow tract obstruction $(\mathrm{n}=2)$, and paravalvular leakage after valve replacement $(\mathrm{n}=1)$. All patients undergoing reoperations had partial cleft closure at the primary procedure, with no

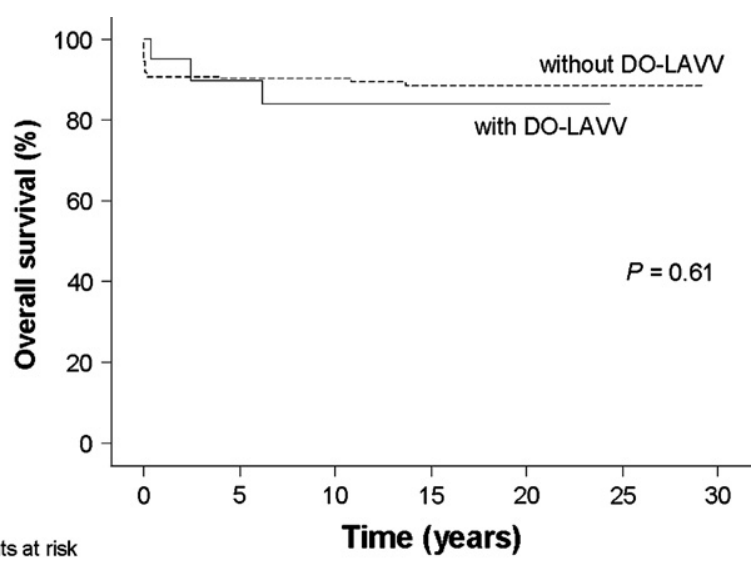

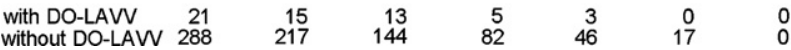

FIGURE 2. Overall survival in patients with atrioventricular septal defect with double orifice left atrioventricular valve ( $D O-L A V V$; solid line) versus patients with atrioventricular septal defect without DO-LAVV (dashed line).

to mild residual regurgitation postoperatively and progressive regurgitation at follow-up. Cox regression analysis showed that cleft closure was not a risk factor for reoperation $(P=.460)$. Both patients with severe regurgitation of the accessory orifice who underwent a different type of repair of the double orifice with resection of the tissue bridge and division of the papillary muscle of the accessory orifice required reoperation (patients 6 and 7, Table 2). In these patients the LAVV was replaced at reoperation because of degenerative changes. At the second reoperation for regurgitation of the true orifice, repair was performed in 1 patient, and replacement was performed in another patient. Two patients required pacemaker implantation after the second reoperation because of a temporary AV block. There was no mortality related to reoperation. The Kaplan-Meier curve for freedom of reoperation is shown in Figure 3. Freedom from reoperation was $62.6 \%$ at 5,10 , and 15 years. The incidence of reoperation in the group with AVSD with DOLAVV was significantly higher than in the group with AVSD without DO-LAVV $(P=.022)$. For patients without DO-LAVV, freedom from reoperation was $88.5 \%, 84.4 \%$, and $80.7 \%$ at 5,10 , and 15 years, respectively.

\section{Clinical Condition}

At the last follow-up, all 18 survivors were in New York Heart Association functional class I without medication. All patients were in sinus rhythm. The last echocardiographic Doppler studies revealed mild residual left AV valve insufficiency to be present in 1 patient.

\section{DISCUSSION}

DO-LAVV is a rare but important anomaly and has been found in association with bicuspid aortic valve, aortic coarctation, and, most commonly, AVSD. ${ }^{4-7}$ Earlier studies reported incidences of DO-LAVV of $2 \%$ to $8.6 \%$ among 


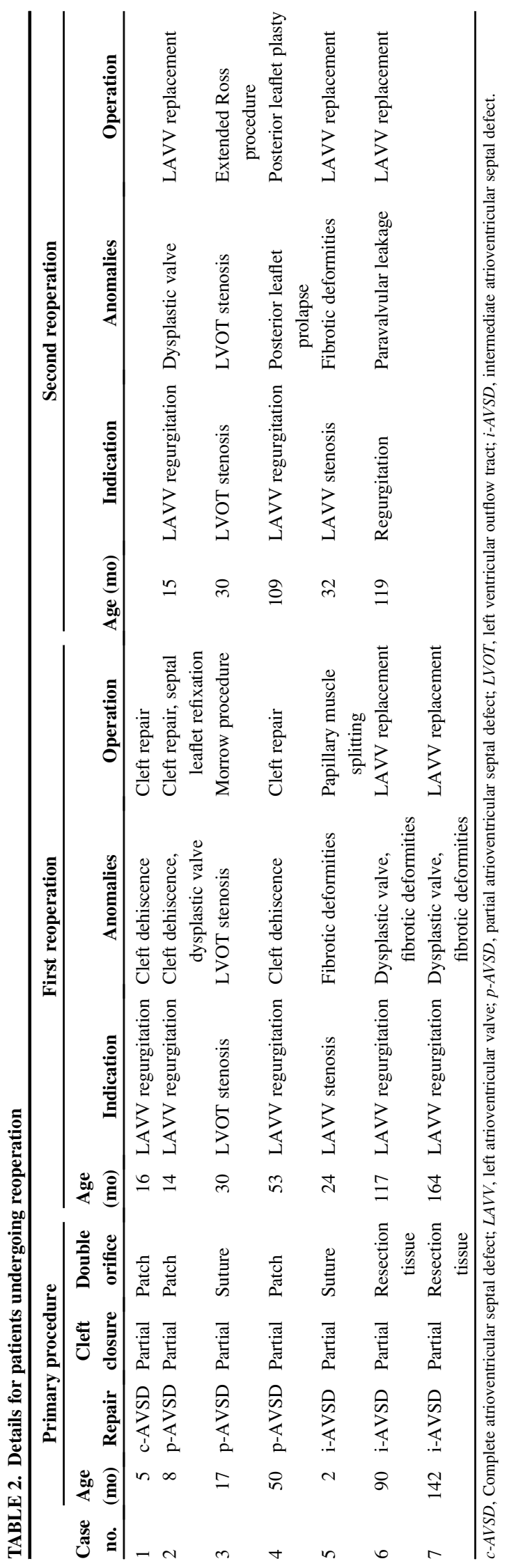

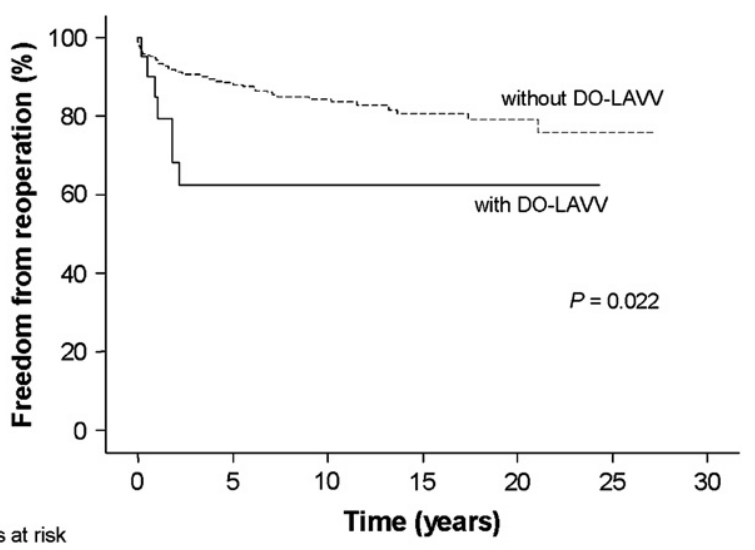

Patients at risk

$\begin{array}{lrrrrrrr}\text { with DO-LAW } & 21 & 10 & 10 & 4 & 3 & 0 & 0\end{array}$

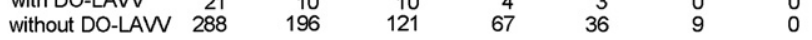

FIGURE 3. Freedom from reoperation in patients with atrioventricular septal defect with double-orifice left atrioventricular valve (DO-LAVV; solid line) versus patients with atrioventricular septal defect without DOLAVV (dashed line).

patients with AVSD. ${ }^{5,8-16}$ In our patients we found an incidence of $6.7 \%$. AVSD with DO-LAVV might present in a wide spectrum of varieties. ${ }^{17} \mathrm{~A}$ characteristic anatomic feature of AVSD with DO-LAVV is convergent chordal insertion instead of normal divergent insertion into 2 foci of insertion. The chords of both the true orifice and the accessory orifice insert into their own focus of insertion, with the chords of the accessory orifice forming a "parachute." According to the operation reports in our series, the accessory orifices were located either in the posterior bridging leaflet (sometimes very near the junction of the posterior bridging leaflet and the mural leaflet; $\mathrm{n}=18$ ) or in the anterior bridging leaflet (sometimes very near the junction of the anterior bridging leaflet and the mural leaflet; $\mathrm{n}=3$ ). It has also been reported by others that the location of the accessory orifice was most often found in the posterior bridging leaflet. ${ }^{18}$

Two patients with severe regurgitation of the accessory orifice had a different type of repair of the double orifice, with resection of the tissue bridge and division of the papillary muscle of the accessory orifice. These 2 patients needed reoperations because of important regurgitation. At the time of reoperation, secondary degenerative changes of the papillary muscle made valve replacement necessary.

Other authors have also mentioned that division of the bridging tissue might cause regurgitation, resulting in valve replacement or operative death. ${ }^{19-21}$ The complexity makes effective repair difficult and might contribute to postoperative valve dysfunction, reoperation, and mortality. Moreover, accessory orifices are seldom more than mildly incompetent. Therefore our current opinion is that the best surgical results are obtained by saving the tissue bridge and tension apparatus and repairing the $\mathrm{AV}$ valve as a 3-leaflet valve. ${ }^{22}$ The accessory orifice is best left untouched. The accessory orifice is most often small in size 
and does not contribute much to the total effective valve orifice area.

Therefore a suture or patch closure is indicated in the rare circumstances in which the accessory orifice is insufficient. To prevent stenosis insufficiency of an incompetent accessory orifice, one might consider using resection of secondary chords or splitting of papillary muscles to increase leaflet mobility and thus coaptation of the leaflets.

AVSD with DO-LAVV has been considered in the past to be a significant risk factor for mortality and reoperation. Reported mortality rates show important differences ranging from $20 \%$ to $50 \%{ }^{5,8,14-16}$ In our series of 21 patients, there was no early mortality. There were 3 late deaths, of which 2 were noncardiac. AVSD with DO-LAVV had no influence on mortality when compared with repair of AVSD without DO-LAVV. However, the incidence of reoperations in patients with AVSD with DO-LAVV was significantly higher than in the group of patients with AVSD without DOLAVV. The most likely explanation for reoperation in 2 patients with intermediate AVSD is the resection of the tissue bridge between the 2 orifices and the division of the papillary muscle, which had led to secondary degenerative changes and valve incompetence.

Lie and colleagues ${ }^{19}$ reported that patients with intermediate AVSD and DO-LAVV had a poor prognosis compared with those with a partial or complete defect. Lee and associates, ${ }^{7}$ in contrast, reported 2 reoperations in patients with partial AVSD in a study of 25 patients with DO-LAVV. Nakano and coworkers ${ }^{18}$ reported that DO-LAVV was a significant predictor for reoperation in patients with partial AVSD. One of the explanations in these studies was that the additional valvular and subvalvular abnormalities might contribute to worse surgical results in patients with partial AVSD and intermediate AVSD with DO-LAVV. In our study 3 patients with partial AVSD and DO-LAVV had a less developed mural leaflet.

In most cases the accessory orifice in patients with DOLAVV is competent, and therefore the focus should be directed on the cleft between the bridging leaflets in the LAVV. Surgical closure of the cleft in patients with AVSD reduces the incidence of LAVV regurgitation, reoperation, and mortality. In patients with DO-LAVV, the cleft is closed to such an extent that regurgitation is managed optimally without creating a valvular stenosis. In our study all patients who required reoperation because of LAVV regurgitation had undergone partial cleft closure. Cleft closure, though, was shown not to be a significant risk factor for reoperation, but patient numbers were relatively small. Therefore based on our experience we prefer to accept a mild regurgitation rather than to create a significant stenosis.

The double-orifice malformation can be repaired with low mortality but is a risk factor for reoperation. Most accessory orifices are competent and can be left untouched. If needed, regurgitation of the accessory orifice is best managed with suture or patch closure.

\section{References}

1. Gunther T, Mazzitelli D, Haehnel CJ, Holper K. Long-term results after repair of complete atrioventricular septal defects: analysis of risk factors. Ann Thorac Surg. 1998;65:754-60.

2. Boening A, Scheewe J, Heine D, Hedderich J. Long-term results after surgical correction of atrioventricular septal defects. Eur J Cardiothorac Surg. 2002;22:167-73.

3. Abbruzzese PA, Napoleone A, Bini RM, Annecchino FP. Late left atrioventricular valve insufficiency after repair of partial atrioventricular septal defects: anatomical and surgical determinants. Ann Thorac Surg. 1990;49:111-4

4. Bano-Rodrigo A, Van Praagh S, Trowitzsch E, Van Praagh R. Double-orifice mitral valve: a study of 27 postmortem cases with development, diagnostic and surgical considerations. Am J Cardiol. 1988;61:152-60.

5. Ilbawi MN, Idriss FS, DeLeon SY, et al. Unusual mitral valve abnormalities complicating surgical repair of endocardial cushion defects. J Thorac Cardiovasc Surg. 1983;85:697-704.

6. Warnes C, Somerville J. Double mitral valve orifice in atrioventricular defects. Br Heart J. 1983;49:59-64.

7. Lee CN, Danielson GK, Schaff HV, Puga FJ, Mair DD. Surgical treatment of double-orifice mitral valve in atrioventricular canal defects. Experience in 25 patients. J Thorac Cardiovasc Surg. 1985;90:700-5.

8. Hanley FL, Fenton KN, Jonas RA, et al. Surgical repair of complete atrioventricular canal defects in infancy. Twenty-year trends. J Thorac Cardiovasc Surg. 1993; 106:387-94.

9. Baufreton C, Journois D, Leca F, Khoury W, Tamisier D, Vouhe P. Ten-year experience with surgical treatment of partial atrioventricular septal defect: risk factors in the early postoperative period. J Thorac Cardiovasc Surg. 1996;112:14-20

10. Najm HK, Caldarone CA, Smallhorn J, Coles JG. A sutureless technique for the relief of pulmonary vein stenosis with the use of in situ pericardium. $J$ Thorac Cardiovasc Surg. 1998;115:468-70.

11. El-Najdawi EK, Driscoll DJ, Puga FJ, et al. Operation for partial atrioventricular septal defect: a forty-year review. J Thorac Cardiovasc Surg. 2000;119:880-9.

12. Abbruzzese PA, Napoleone A, Bini RM, Annecchino FP, Merlo M, Parenzan L. Late left atrioventricular valve insufficiency after repair of partial atrioventricular septal defects: anatomical and surgical determinants. Ann Thorac Surg. 1990;49:111-4.

13. Giamberti A, Marino B, di Carlo D, et al. Partial atrioventricular canal with congestive heart failure in te first year of life: surgical options. Ann Thorac Surg. 1996;62:151-4.

14. Michielon G, Stellin G, Rizzoli G, Casarotto DC. Repair of complete common atrioventricular canal defects in patients younger than four months of age. Circulation. 1997;96(suppl):II316-22.

15. Najm HK, Coles JG, Endo M, et al. Complete atrioventricular septal defects: results of repair, risk factors, and freedom from reoperation. Circulation. 1997; 96(suppl):II311-5.

16. Brando K, Turrentine MW, Sun K, et al. Surgical management of complete atrioventricular septal defects. A twenty-year experience. J Thorac Cardiovasc Surg. 1995; 110:1543-52.

17. Draulans-Noe Y, Wenink ACG, Quaegebeur J. Single Papillary Muscle and double orifice left ventricle in atrioventricular septal defect convergence of chordal attachment: surgical anatomy and results of surgery. Pediatr Cardiol. 1990;11: 29-35.

18. Nakano T, Kado H, Shiokawa Y, Fukae K. Surgical results of double-orifice left atrioventricular valve associated with atrioventricular septal defects. Ann Thorac Surg. 2002;73-1:69-75.

19. Lie C-N, Danielson G, Schaff H, Puga F, Mair D. Surgical treatment of double orifice mitral valve in atrioventricular canal defects. $J$ Thorac Cardiovasc Surg. 1985;90:700-5.

20. Warnes C, Somerville J. Double mitral valve orifice in atrioventricular defects. $\mathrm{Br}$ Heart J. 1983;49:59-64.

21. Wigle ED. Duplication of the mitral valve. Br Heart J. 1957;19:296-300.

22. Carpentier A. Surgical anatomy and management of a mitral component of atrioventricular canal defects. In: Anderson RH, Shinebourne EA, eds. Paediatric cardiology 1977. Edinburgh: Churchill Livingstone; 1978:477-86. 